\title{
O peão de trecho e o peão de casa: identidade operária entre os trabalhadores da construção civil de Barcarena no canteiro de obras da ALBRAS/ALUNORTE*
}

Edilza Fontes - Professora do Departamento de História da Universidade Federal do Pará (UFPA) e doutoranda em História Social do Trabalho na Universidade Estadual de Campinas.

\section{Resumo}

Este artigo pretende discutir as relações entre o projeto ALBRAS/ ALUNORTE e o processo de organização sindical dos trabalhadores da construção civil de Barcarena, no momento da construção da fábrica da ALBRAS. Analisam-se as relações de trabalho nos canteiros de obras e discutem-se as idéias de modernidade e de progresso que os trabalhadores expressaram nos momentos de conflito com os empresários da construção civil, com o governo do Pará e com o projeto de desenvolvimento para a região, nas greves ocorridas no setor em 1984 e 1985.

\section{Abstract}

This article intends to discuss the relations among the ALBRAS/ALUNORTE and the syndical organization process of Barcarena civil construction workers, at the moment of the ALBRAS plant construction. The work relations has been analyzed in the work area and discussed the both modernity and progress ideas whose workers express during the moments conflicts with the civil construction contractor, with the Pará Government as well as the region development project, in the strikes occurred over the 1984 and 1985 period.
Palavras-chave

Projeto de desenvolvimento, mineração e relações de trabalho.

\section{Keywords}

Project development, mining and labour relations. 


\section{INTRODUÇÃO}

A análise dos grandes projetos na Amazônia apóia-se, neste artigo, na discussão da construção de uma identidade operária com base no entendimento da visão de mundo dos trabalhadores da construção civil, tentando perceber suas ações e seus olhares em relação ao projeto de modernização do governo brasileiro nas últimas décadas na região. Não pretendemos ter somente uma visão de cima, que minimize a presença dos sujeitos históricos; procuramos antes conhecer as concepções dos trabalhadores para abrir caminhos que revelem outras dimensões dos grandes projetos na Amazônia, como o cotidiano do trabalho, as experiências da organização sindical e da moradia em alojamentos. Reelaboradas pelos trabalhadores, essas dimensões permitiram ações grevistas dentro dos canteiros de obras de um grande projeto.

A análise procura demonstrar que pode e deve ser estudado o olhar dos próprios trabalhadores sobre processos que interferem nas suas vidas. Esse outro olhar questiona análises que usualmente esquecem os sujeitos e concebem as relações sociais como relações meramente quantitativas, transformando os trabalhadores em força de trabalho. Essas análises estruturais dos processos de trabalho acabam tendo uma visão de cima, que só atenta para a relação matéria-prima, para a produção.

Este artigo pretende analisar o projeto ALBRAS/ALUNORTE com base nas relações historicamente construídas pelos trabalhadores da construção civil de Barcarena, que articularam suas lutas reivindicatórias e, apesar de suas diferenças, construíram uma identidade operária, o que ensejou seis anos de greves (1985/1989), que, por vezes, paralisaram a construção da fábrica da ALBRAS e da Vila dos Cabanos.

Em linhas gerais, podemos afirmar que a região do Baixo-Tocantins vive o impacto provocado pela instalação dos projetos industriais, ligados ao grande projeto Carajás. Há cada vez mais a concentração e a monopolização da terra por grandes empresas e a conseqüente formação de uma população flutuante, que se desloca para as periferias urbanas de Abaetetuba, Barcarena e Vila do Conde. Essa população serve de mãode-obra abundante e barata, principalmente na construção civil. A estratégia dos governos brasileiros para o desenvolvimento da Amazônia inclui também a implementação, em âmbito regional, na região do BaixoTocantins, de projetos agroindustriais de dendê, coco e seringa (no município de Moju), além da construção da fábrica da ALBRAS e da ALUNORTE. Esses projetos, indústrias e agroindústrias trouxeram vultosos investimentos para o Pará. No município de Barcarena, foi construída a fábrica da ALBRAS, que produz alumínio, além da infraestrutura necessária ao funcionamento dessa fábrica, destacando-se o porto de Ponta Grossa, com capacidade para navios de grande calado, que podem transportar até 400.000 toneladas do produto da ALBRAS. 
O Estado criou as condições de infra-estrutura necessárias: hidroelétrica, porto, estradas e o núcleo habitacional, a Vila dos Cabanos, assim como $60 \mathrm{~km}$ de sistema viário, $30 \mathrm{~km}$ de drenagem, $30 \mathrm{~km}$ de rede de água, $50 \mathrm{~km}$ de rede elétrica, sistema de telecomunicação e 30 km de rede de esgoto sanitário, hospital, escolas, centro de reserva de água, centro esportivo, cinema/auditório, estação rodoviária e posto policial. O núcleo habitacional de Vila do Conde tem capacidade para 70.000 pessoas, ligadas diretamente à ALBRAS.

A ALBRAS foi concebida para atuar conjuntamente com outra fábrica, a ALUNORTE, com a função de produzir a matéria-prima indispensável à produção de alumínio. A ALBRAS entrou em operação em julho de 1985, importando alumina do Suriname . A mão-de-obra diretamente empregada pelas duas fábricas, segundo a direção da fábrica, mais o porto, seria de 11.306 trabalhadores. A implantação do núcleo urbano esteve a cargo da Companhia de Desenvolvimento de Barcarena (CODEBAR). O núcleo urbano é uma cidade planejada, com infra-estrutura, com equipamentos urbanos e comunitários, quartel da Polícia Militar (PM) e setor comercial.

No município de Barcarena, em contrapartida, desenvolveu-se um cinturão de miséria: a sede do município e três pequenas vilas transformaram-se rapidamente em aglomerados urbanos, sem as condições infra-estruturais para receber a população que chega à região. Em 1985, a cidade já contava com 25.000 habitantes; em 1989, essa população chegou a 100.000 habitantes. A cidade de Barcarena recebeu um grande número de agricultores (em torno de 20.000) que, por terem sido desapropriados, recorreram ao assalariamento na construção civil e à venda ambulante no comércio de Vila do Conde, Itupanema e São Francisco. Os desapropriados construíram um bairro, o Bairro Novo, sem infra-estrutura alguma.

A deterioração das condições de moradia no município de Barcarena é hoje, em nossa opinião, uma das mais desastrosas conseqüências da implantação do projeto ALBRAS/ALUNORTE sob vários pontos de vista: a estética, as comodidades da população, o saneamento e a densidade demográfica. Para Barcarena vieram trabalhadores de todas as partes, em busca de empregos, de salários, devido à propaganda do governo que apregoava as ótimas condições para a melhoria de vida. Era uma forma de atrair a população para o município.

Os operários de Barcarena que trabalharam nas obras de infraestrutura do complexo industrial ALBRAS/ALUNORTE caracterizavamse pela mobilidade, pela experiência de trabalho em outros projetos (o

${ }^{1}$ Em razão do atraso na construção da fábrica da ALUNORTE. 
peão de trecho) e pela inexperiência de parte da categoria, que estava fichando pela primeira vez (o peão cabaço) ${ }^{2}$. Em outubro de 1984, esses trabalhadores nos canteiros de obras eram 12.000, número que caiu para 7.000 em 1985, devido à conclusão da primeira fase da ALBRAS. Esses trabalhadores foram contratados pelas 50 empreiteiras, e quase todos eram residentes nos alojamentos específicos, instalados no bairro Pioneiro da Vila dos Cabanos.

No discurso oficial, a região Amazônica caminha a passos largos rumo ao desenvolvimento. O progresso é visto como a meta a ser atingida com os grandes projetos na região. Esses projetam representam o caminho para a mudança e para o desenvolvimento. O progresso é resultado dos empreendimentos econômicos de porte gigantesco, que, segundo esse discurso, garantem o crescimento da região e o bemestar do povo. Os homens e o desenvolvimento são dois elementos de um mesmo discurso oficial que defende a crença no progresso industrial e vende a imagem de um novo ciclo de vida na Amazônia.

Na proposta do governo, os projetos para a Amazônia esquecem os homens como seres, que se constroem em contextos delimitados, no tempo e no espaço, e que constituem suas subjetividades em processos sociais e históricos. Nos planejamentos das políticas de desenvolvimento para a região, os homens são sujeitos abstratos, eternos, imóveis e idênticos, não são homens tomados no contexto das suas sociedades. Por essa razão, tais projetos não estão de acordo com a vivência concreta dos habitantes da Amazônia. Esses projetos continuam presos a categorias abstratas de identidades universais, como "desenvolvimento" e "progresso"; dessa maneira, concebem a história da região como um processo linear, evolutivo e universal.

O conceito de modernidade, nos discursos oficiais, encerra a crença na implantação de uma forma racional de mudança na história da região, que aponta para um futuro industrial, cujas bases de sustentação desconhecem a tradição de vida dos habitantes da Amazônia. Não há críticas à modernidade proposta, porque é pressuposta como a razão e como a única verdade possível. A proposta do projeto ALBRAS/ ALUNORTE, no momento da sua implantação, carregava a imagem de uma modernidade linear e finalista, ou seja, envolvia a idéia de aceleração do movimento e do tempo, para reverter o atraso da região, movendo a história e predizendo o futuro.

A história é chamada para referendar o presente, na medida em que é rememorada como instrumento de reelaboração da imagem de mudança, de revolução e de novos caminhos no presente. Ao nomear o

\footnotetext{
2 "Peão cabaço" era a expressão usada pelo peão de trecho para designar o trabalhador da construção civil que pela primeira vez era cadastrado (fichado) em uma empresa.
} 
núcleo urbano de Vila dos Cabanos, o governo utiliza-se mais uma vez da história para estabelecer um paralelo impossível entre as aspirações de mudanças sociais do movimento da Cabanagem e o projeto ALBRAS/ ALUNORTE. Esse projeto tenta apresentar-se à sociedade como o redentor dos ideais cabanos, que seriam retomados, para redimir a Amazônia de seu abandono. A memória da Cabanagem é utilizada para mais uma vez sufocar os gritos dos mortos e tentar calar os vivos sobre as possíveis críticas à modernidade proposta.

Apesar do discurso oficial, na menor das hipóteses, o governo jogou 120 milhões de dólares na área do projeto (PINTO, 1986), para criar uma indústria privada, que se beneficiou de obras construídas com dinheiro público. Logo, toda a infra-estrutura criada serve apenas para exportar alumínio. Dessa forma, o discurso oficial mostrou-se falacioso, na medida em que a velha função de colônia exportadora continua sob outra forma, como afirma Lúcio Flávio Pinto (1986):

Em Barcarena não ha pólo metalúrgico, não surgiram indústrias complementares, o lingote não foi desdobrado em produtos mais nobres e a porta permanece sendo apenas uma plataforma de uma riqueza, a realimentar (retroalimentar seria a expressão mais adequada) nossas desiguais relações de troca com o outro lado.

Neste artigo, pretendo analisar os grandes projetos na Amazônia com base nos sujeitos que viveram a experiência da construção da fábrica da ALBRAS. Trata-se, portanto, de uma discussão conjuntural, restrita e específica, que visa estudar e redescobrir os papéis dos sujeitos históricos envolvidos em situações inéditas e atípicas, o que possibilita a análise de processos sociais dentro de um grande projeto na Amazônia. Procuro, dessa maneira, discutir as formas de ver e conceber a Amazônia com base em um modo de conhecer segundo o qual os homens são, apesar dos condicionantes, agentes de si mesmos (DIAS, 1992).

Busco analisar os processos ocorridos à luz de um conhecimento relacional, dialético e narrativo. Neste artigo, almejo narrar os eventos, como as greves ocorridas no canteiro de obras da ALBRAS/ALUNORTE, nos anos de 1984 e 1985, e interpretar os conceitos dos trabalhadores da construção civil, por entender que tais conceitos são em si mesmos um campo de significados (KOSELLECK, 1951).

Os trabalhadores historiam os seus próprios conceitos, com base em suas experiências de vida. Já em 1983 os operários realizavam greves parciais no canteiro de obras da ALBRAS. Nas greves realizadas nas empresas M. Roscoe e Sermeco, vários trabalhadores foram despedidos. As empresas elaboraram uma lista negra, não admitindo a contratação de operários identificados como líderes dessas greves. Vários operários 
despedidos, que tinham seus nomes na lista negra, reuniram-se em Abaetetuba e resolveram fazer uma denúncia pública dessa lista e de outras irregularidades que aconteciam nas obras de Vila do Conde.

A carta-denúncia foi assinada pela Associação Profissional dos Trabalhadores nas Indústrias da Construção Civil de Barcarena, pela Diocese de Abaetetuba, pela Pastoral Operária de Belém e pela Sociedade Paraense de Defesa dos Direitos Humanos (SDDH). Foi entregue ao deputado Gabriel Guerreiro do PMDB, aos jornais, ao radialista Adamor Filho e à Delegacia Regional do Trabalho (DRT). Os sete operários que levaram a carta a Belém, no dia 17 de agosto de 1983, relataram, em assembléia da Associação, que o governador Jader Barbalho prometeu tomar providências, que o radialista leu as denúncias por dois dias no rádio, que o deputado fez um discurso na assembléia e propôs a vinda de uma comissão para averiguar as denúncias e que a DRT afirmou que já tinha enviado para Barcarena dois fiscais.

Esse tipo de iniciativa repetiu-se várias vezes no movimento reivindicatório dos trabalhadores da construção civil. Graças à discussão constante sobre direitos trabalhistas não respeitados, foi sendo forjada uma identidade operária. A denúncia à opinião pública foi a forma que esses trabalhadores encontraram para reafirmar seus direitos e assumirse como parte de uma sociedade. As condições de trabalho, nos canteiros de obras da ALBRAS, foram o tema comum da discussão de uma identidade entre os trabalhadores, que tinham experiências diferenciadas de vida, tanto no que diz respeito ao mundo do trabalho, como em relação às suas trajetórias de vida. Da categoria faziam parte muitos peões de trecho, que haviam passado por outras experiências em outros projetos, assim como um número razoável de trabalhadores vindos do campo, que pela primeira vez enfrentavam o assalariamento, alguns eram trabalhadores autônomos e ainda viam sua profissão como uma arte.

As obras da ALBRAS exigiram uma grande concentração de trabalhadores no município de Barcarena. Esses trabalhadores ficaram alojados nos canteiros de obras, em barracões construídos pelas empresas. Esse tipo de moradia permitia um maior controle por parte das empresas e uma disciplina bastante rígida, o que freqüentemente possibilitou abusos, inclusive espancamento de trabalhadores que se recusavam a obedecer às ordens dos chefes de seções.

O controle da mão-de-obra era exercido pelos seguranças das empresas, que dentro dos alojamentos ficavam atentos a qualquer movimentação reivindicatória. Houve casos em que trabalhadores foram demitidos por estarem distribuindo o Zé Pião, boletim informativo da Associação Profissional dos Trabalhadores da Indústria de Construção Civil de Barcarena. 
Outra dificuldade que os trabalhadores enfrentavam dizia respeito à alimentação. As empresas descontavam a alimentação do salário dos trabalhadores e ofereciam uma refeição de péssima qualidade, que por vezes era motivo de protestos. Houve mesmo uma situação extrema: policiais da PM, armados, obrigaram trabalhadores da ENGEPLAN a comer comida estragada, que eles tentaram recusar. As condições de transporte eram as mais precárias possíveis, os trabalhadores eram transportados em caminhões sem bancos e sem cobertura (os "cata cornos"). Acidentes no trabalho eram freqüentes, o que se agravava pela falta de atendimento médico nos canteiros, onde geralmente não se encontravam médicos ${ }^{3}$.

Os direitos trabalhistas eram constantemente desrespeitados pelas empresas. Eram poucas as empresas que não obrigavam seus trabalhadores a bater ponto na hora do almoço. As empresas TENEGE, TECHINT, FRANK e SERVENG eram as mais rígidas em relação ao cumprimento do horário. A questão salarial era a principal reivindicação dos trabalhadores. Durante o ano de 1983, as empresas pagavam a seus empregados um salário diferente para o mesmo grupo de profissionais, e já na negociação coletiva de 1983 o salário foi unificado. Os trabalhadores conquistaram o piso salarial para cada função, a data base e o dia do trabalhador da construção civil como feriado, com direito a remuneração, além de dois salários mínimos para a esposa que ficasse viúva e transporte para os locais de moradia. Esses direitos elementares do trabalhador foram lesados pelas empresas que estavam construindo o projeto da modernidade em Barcarena.

Documentar a vida dos trabalhadores da construção civil de Barcarena, suas experiências de vida nos canteiros de obras, suas visões de mundo e suas concepções de direitos é tentar estudar um processo importante, até aqui invisível em análises que primam pelas discussões estruturais. A historiografia sobre a classe operária costuma entender a mobilidade dos trabalhadores como um dos obstáculos para a organização sindical e para a constituição de uma consciência de classe em categorias como a da construção civil. Ocorre que o capital, na medida em que se internacionaliza, cria condições para a constituição de um mercado de trabalho altamente rotativo, o que já se observava no início do século nos grandes canteiros de obras do mundo inteiro. Exemplos disso foram as construções das ferrovias, dos portos e das estradas .

\footnotetext{
${ }^{3}$ Todas as informações sobre condições de trabalho, moradia e campanhas salariais foram retiradas da coleção de Zé Pião, dos relatórios da Federação de Órgãos para Assistência Social e Educacional (FASE) e de entrevistas realizadas com os diretores da Associação Profissional dos Trabalhadores da Indústria de Construção Civil de Barcarena.

${ }^{4}$ Um bom exemplo dessa discussão é o livro de Francisco Foot Hardman, Trem fantasma: a modernidade na selva (1988).
} 
Em Barcarena, o mercado de trabalho é portador de uma cultura operária que difere da cultura de uma classe operária fixada, que reside perto do local de trabalho e participa de uma empresa por muito tempo. O trabalhador peão que não tem uma profissão e não pára por muito tempo em uma empresa, devido às peculiaridades do seu trabalho, passa boa parte do seu tempo à procura de emprego, correndo trecho. É possível, porém, definir uma identidade operária que o assuma como profissional, constituinte de uma classe em constante movimento espacial, e lhe permita desempenhar um papel fundamental no movimento reivindicatório, na medida em que conhece o movimento do capital e as suas estratégias de organização do trabalho.

Um grande número de trabalhadores de trecho foi reunido pelo capital nos canteiros de obras da ALBRAS. Trabalhadores de Minas Gerais, da Bahia, do Maranhão, do Piauí, de Pernambuco, do Ceará e dos mais variados lugares do Brasil. Trabalhadores que tinham participado da construção de projetos como Tucuruí, Paulo Afonso, Sobradinho, Balbina e outros empreendimentos do grande capital no Brasil. As experiências desses trabalhadores foram confrontadas com as dos trabalhadores da região que, na sua grande maioria, não tinham participado de qualquer trabalho assalariado, muitas vezes ainda estavam presos a sua trajetória camponesa, com expectativas em relação aos patrões, construídas sobre valores morais, como honra e lealdade.

A moradia nos alojamentos permitia um maior contato entre os trabalhadores de trecho e os trabalhadores dos municípios vizinhos, que só voltavam para casa nos fins de semana. O alojamento era o espaço do trabalho, mas era também o espaço da troca de experiências, da reflexão sobre as condições de vida e de trabalho. O alojamento permitia um certo controle por parte dos capitalistas, mas criava condições de reunião de todos os trabalhadores de uma mesma empresa fora do ambiente do trabalho. Apesar das tentativas de controlar a utilização desse espaço, aí se expunha a organização da empresa e seu capital perante um grande número de operários. Era no alojamento que os operários tomavam conhecimento de toda a organização do trabalho da empresa; era no alojamento que ficavam sabendo dos acidentes ocorridos nos canteiros de obras, das atitudes tomadas por mestres-de-obras, das condições de trabalho das outras empresas, das condições de alimentação dos restaurantes, etc.

As campanhas salariais eram discutidas nos alojamentos que, diferentemente da vila operária, eram um espaço coletivo por excelência; não eram o espaço do lar da família, mas eram o espaço de uma família maior, que permitia que se constituísse uma classe. Os trabalhadores, como resultado de experiências comuns (herdadas ou partilhadas), 
descobriram a identidade de interesses entre si, contra outros homens (seus patrões), a cujos interesses se opunham, e construíram uma consciência de suas vidas, uma consciência de classe, a partir do momento em que forjaram formas de identidade que expressam seus valores, suas idéias e lutas (THOMPSON, 1987).

Esse tipo de moradia constitui uma dada cultura operária. Um dos elementos dessa cultura operária é o jogo de futebol dos domingos, quando times de empresas disputam grades de cervejas. O jogo de futebol - a pelada - é um espaço de lazer construído pelos trabalhadores, no qual a disciplina e a organização estabelecem uma forma de relacionamento entre trabalhadores de uma mesma empresa, fora do espaço do trabalho. Em Barcarena, os jogos não eram institucionalizados pelas empresas e foram motivos de confronto, porque as empresas exigiam de cada trabalhador um determinado número de horas extras. Ora, os trabalhadores queriam definir como usar o seu tempo livre e não aceitavam a tentativa de interferência em seu lazer.

A cultura do alojado inclui o comer junto e o recusar comida estragada, a luta por um cardápio comum, a saúde sendo reivindicada como um dos direitos de cidadania. Trata-se de uma cultura que expressa solidariedade aos companheiros que estão urrando , "passando a sacola" ou arranjando um meio de colocar o companheiro nos alojamentos, sem que a segurança das empresas veja. É uma cultura operária que socorre os trabalhadores doentes nos alojamentos ou recolhe fundos para seu tratamento ou funeral. É uma cultura operária que estabelece uma relação com a sociedade local ao participar de suas festas religiosas.

Denúncias de bebedeiras e práticas de sedução de menores por parte dos trabalhadores da construção civil eram freqüentes. Parte da sociedade local - as igrejas e crenças evangélicas - via, com reservas, alguns hábitos dos trabalhadores da construção civil. A pastoral operária e as igrejas evangélicas do município tentavam condenar o jogo, o alcoolismo e o relacionamento sexual aberto. Viam essas práticas como um relaxamento moral, que desagregava a família. A família, para esses trabalhadores, representava a garantia de uma identidade, um porto seguro ao qual se retorna a cada viagem, nos fins de semana ou no término da construção.

A proliferação da prostituição nas áreas de grandes projetos é característica de um tipo de organização do trabalho que, para se sustentar, necessita reunir um grande número de trabalhadores, que ficam distantes de suas esposas, o que enseja relações afetivas

\footnotetext{
${ }_{5}^{5}$ Termo usado pelos trabalhadores para designar os trabalhadores que estavam no projeto e não tinham onde ficar, até serem fichados, ou seja, serem cadastrados para possível recrutamento pelas empresas.
} 
esporádicas. Faz parte da cultura do trabalhador de grandes projetos o estabelecimento de relações amorosas em cada trecho em que trabalha. Essa cultura é tão forte que é motivo de separação judicial - quando a mulher emprega-se nas empresas prestadoras de serviços nos alojamentos (geralmente como faxineiras, lavadeiras ou cozinheiras). O perigo da traição é constante e revela a insegurança da mulher sem a proteção do marido. Estabelece-se um jogo para saber quem consegue conquistar a faxineira. É inadmissível que uma mulher freqüente o alojamento sem ter sido "cantada" por alguém.

A cultura do garanhão que "transa com todas" e "não é chifrudo" é um elemento cultural importante para a aceitação de uma liderança nos canteiros de obras. As prostitutas eram disputadas nos fins de semanas, na Vila do Conde. Vinham de Belém e, por vezes, emprestavam seus quartos a trabalhadores que estavam urrando nos canteiros de obras, eram tratadas com o respeito devido, no sentido de receber o pagamento pelos seus serviços. Algumas vezes, eram transformadas em enfermeiras ou em mensageiras entre uma obra e outra. Elas tinham trânsito livre nos canteiros de obras, o que possibilitava passar a seus clientes informações sobre a realização de assembléias da associação. Aliás, o espaço do bordel, do prostíbulo ou do outeiro, como é chamado nas áreas dos grandes projetos, várias vezes foi utilizado para conversas rápidas sobre as campanhas salariais, assim como para a leitura do Zé Pião.

No Zé Pião, a oposição entre os empresários e os trabalhadores representa o tempo todo um campo de contradições, em que a exploração é exercida:

A situação dos trabalhadores dos canteiros de obras não é lá essas coisas, falta transporte, comida, o salário é pouco, o médico é como um cometa (só aparece de vez em quando), o patrão tem dinheiro e mais dinheiro, não lhe falta nada. Como pode haver tanta miséria ao lado de tanta riqueza? Nós temos que dizer não a esta situação, temos o direito de viver bem. O peão tem uma vida difícil, só temos como força a nossa união, um peão junto com outros peões não será derrotado, o patrão teve consideração conosco até agora. Nós temos que dar conta dos nossos problemas [...]. COMPANHEIROS, a união é a nossa arma, somos milhões neste Brasil, milhares na Vila do Conde, tentamos resolver as coisas na lei, mas os 'homens' não estão cumprindo as leis. Só nos resta uma saída: a categoria lutar, cruzar os braços até as nossas reivindicações serem atendidas. PARTICIPE DA REUNÃO DE SUA EMPRESA. VAMOS À LUTA (Zé Pião, set. 1984). 
A disciplina do trabalho era deixada de lado nos fins de semana, quando o trabalhador desejava esquecer o relógio, o ponto e a saudade de casa. Os trabalhadores lutavam pelo seu tempo livre, negando-se a trabalhar aos sábados à tarde, reivindicando um pagamento maior para as horas extras ou não acatando a proposta dos patrões de suprimir o dia dos trabalhadores da construção civil (15 de junho). A proposta foi feita nas negociações da campanha salarial de 1984. As empresas argumentavam que as obras já estavam bastante atrasadas e diziamse dispostas a dar ao sindicato e à Federação uma quantia em dinheiro para ajudar nas comemorações dos sindicatos, mas não deveria haver feriado com remuneração garantida. Argumentavam ainda que os trabalhadores aproveitavam o dia para vadiagem e bebedeiras.

O dia do trabalhador da construção civil era um dia de folga no trabalho. Nesse dia, havia torneios de futebol, de dominó, festas nas vilas. Era uma das faces da identidade dos trabalhadores, cristalizada em um símbolo de classe - a identidade de um trabalho era vivenciada no espaço do lazer. Os trabalhadores sabiam que o tempo era importante para as empresas, mas reafirmaram a sua disposição de controlar o seu tempo livre, votando em assembléia geral pela manutenção do seu dia como um dia livre da disciplina do trabalho.

Certos costumes mantiveram-se, como a organização de caçadas e de pescarias nos sábados à noite, a inclusão da farinha de mandioca no cardápio dos alojamentos ou até mesmo do açaí. Outro hábito era tomar café e fumar um cigarro ao redor de uma mesa com os amigos, jogando porrinha ou dominó. Nesses momentos, os trabalhadores costumavam trocar informações sobre as condições de trabalho e sobre as campanhas salariais. Assim, o bar foi usado como espaço de organização dos trabalhadores da construção civil nos canteiros de obras da ALBRAS.

O cinema no terminal rodoviário era uma das diversões preferidas dos alojados. Os filmes quase sempre eram sobre sexo ou sobre lutas de um oprimido contra um inimigo poderoso, em que o herói luta sozinho contra seus inimigos e não pode confiar em ninguém, pois será traído. É a luta solitária e monumental contra o mal. O cinema era uma das armas utilizadas pelos patrões para desmobilizar as assembléias da categoria. Nos dias de reunião, o cinema apresentava um filme novo, que não seria reprisado nos outros dias.

A questão das funções nas profissões da construção civil faz parte da cultura operária do canteiro de obras. As diferenciações profissionais delimitavam espaços bem definidos nas relações de trabalho. A categoria dividia-se em serventes, meio-oficiais, apontadores, almoxarifes, vigilantes e profissionais (carpinteiros, pedreiros, eletricistas, etc.). Essas 
divisões profissionais relacionavam-se com valores ligados à profissão e indicavam diferenciações sociais.

O mestre-de-obras é um profissional que se considera detentor de um conhecimento indispensável ao exercício da profissão. É ele que dirige as turmas de trabalhadores para realizar uma tarefa, ele é o organizador dos pequenos grupos de trabalhadores no canteiro de obras. Ele é geralmente um pedreiro de confiança do engenheiro responsável por uma parte da construção, assim como os eletricistas que comandavam grupos de trabalhadores no serviço de eletrificação da fábrica e do núcleo urbano. Os meio-oficiais eram os ajudantes diretos dos profissionais, que indicam uma certa forma de aprendizado no canteiro de obras. Os serventes eram os ajudantes mais desqualificados e geralmente realizavam serviços como abrir caminhos, carregar pedras, abrir valas, ou seja, os serviços mais pesados.

Essas diferenciações expressavam-se nas discussões sobre salários e sobre quem deveria ser o presidente da Associação. Os profissionais acreditavam ter mais direitos que os serventes e não aceitavam ser dirigidos por um subalterno no trabalho. Essas diferenciações também se expressavam entre os trabalhadores de trecho e os de casa (do local), por conta da questão das ferramentas. Constatou-se que os profissionais de casa ainda seguiam, no exercício da profissão, uma tradição de autonomia e independência em relação ao capital. A questão era a seguinte: as empresas davam preferência aos trabalhadores que carregassem suas ferramentas, mas os peões de trecho recusavam-se a carregar suas ferramentas de obra em obra e levantavam a questão da depreciação de suas ferramentas em favor de uma obra que não era sua - conclui-se que esses peões não se consideram mais trabalhadores autônomos. Já para os trabalhadores de casa, é inviável exercer sua arte com ferramentas que não são suas. Para eles, o importante é a qualidade de seu trabalho, têm orgulho de seu saber, de sua profissão.

Essa discussão demonstra que há sujeitos com experiências diferentes nos canteiros de obras da ALBRAS. O fornecimento das ferramentas pelas empresas só foi conseguido na greve de 1985, quando os membros da categoria já se identificavam como trabalhadores que prestam serviços às empresas, que deveriam fornecer as ferramentas para o exercício do trabalho.

A campanha salarial de 1984 foi fruto de várias assembléias nos locais de moradia e no terminal rodoviário. Na assembléia geral do dia 29 de novembro de 1984, foi votada a greve em todo o canteiro de obras da ALBRAS. Foi a primeira greve que conseguiu parar toda a construção de um grande projeto no Brasil. Essa greve foi decretada após uma semana de negociação salarial. Foi uma greve preparada nos alojamentos e nas vilas de Barcarena. Nas assembléias, foram escolhidos 
os representantes dos operários por empresa que organizariam a greve junto com a Associação.

Uma categoria com o grau de mobilidade da construção civil necessariamente tem de ter uma organização sindical que dê conta dessa movimentação. A organização da Associação foi um trabalho difícil, em virtude das condições impostas pela legislação sindical e pela rotatividade da categoria. A legislação exigia que primeiramente fosse organizada uma associação profissional, que depois seria transformada em um sindicato. Enquanto isso, os acordos coletivos eram fechados pela Federação nos municípios onde não existia sindicato.

A Associação não tinha o direito legal de representar os trabalhadores nas negociações salariais. Mas os diretores da Associação impuseram-se na mesa de negociações, apoiados pela mobilização da categoria. Assim, a greve de 1984 começou quando a Federação fechou um acordo não aceito pelos trabalhadores de Barcarena.

A organização das campanhas salariais envolveu a discussão e a organização dos trabalhadores nos alojamentos e nas vilas como Itupanema, Vila dos Cabanos, Laranjal e São Francisco. As propostas eram discutidas nesses locais, e posteriormente era apresentado um acordo à Federação. Já durante a elaboração das propostas, formava-se uma comissão de negociação composta de trabalhadores por empresa e de alguns membros da diretoria da Associação. Eles tinham estabilidade no emprego (uma das reivindicações da campanha salarial de 1983), o que permitia a constituição de um grupo de trabalhadores que, ficando nos canteiros de obras, fiscalizavam o cumprimento dos acordos coletivos e da legislação trabalhista.

A falta de um sindicato institucionalizado não impediu a organização dos trabalhadores e suas ações grevistas. Mas essas ações só foram possíveis porque a organização do trabalho foi relembrada. A própria identidade operária, nos canteiros de obras, foi construída a partir dos processos de organização do trabalho.

A repressão do Estado era sentida pela presença da polícia nos canteiros de obras. Mais de 200 PM do Estado foram enviados aos canteiros de obras e destruíram as barricadas que foram armadas na noite do dia 29 de novembro. Essas barricadas foram construídas no meio das estradas, tentando impedir a entrada dos trabalhadores de casa nos canteiros de obras. Foram feitas com toras de madeira, retiradas dos canteiros de obras que, naquele momento, passou a ser ocupado pelos trabalhadores em greve.

Os trabalhadores, naquele momento, apropriaram-se dos conhecimentos que tinham sobre o processo de trabalho e mudaram sua utilização. Quando perceberam que era impossível tentar fazer 
piquetes em todas as obras, resolveram ocupar a fábrica da ALBRAS, assumindo assim o poder no interior da fábrica, dando uma demonstração de conhecimento do projeto e colocando em perigo, só com a sua presença, o projeto da ALBRAS. Promoveram verdadeiros "arrastões" dentro da fábrica e nos canteiros de obras, alertando os donos do capital dos riscos de depreciação das máquinas e de inviabilização do projeto.

A greve forçou a realização de novas negociações no campo do trabalho. De fato, as negociações passaram a realizar-se nos escritórios da fábrica, o que favorecia as ações diretas de pressão em relação aos patrões. Essa greve foi organizada no momento em que os trabalhadores já possuíam uma vivência nos canteiros de obras e conheciam os prazos que as empreiteiras tinham com a ALBRAS. Os trabalhadores mudaram o calendário da obra e estabeleceram o seu ritmo, o seu tempo. A existência de temporalidades diferentes expressa-se na forma de estabelecer o tempo do trabalho e o tempo da greve. A própria ocupação da ALBRAS representa uma estratégia de pressão na fábrica, para que esta pudesse pressionar as empresas. Os trabalhadores tinham também conhecimento dos recursos tecnológicos que estavam sendo colocados em perigo.

No primeiro dia de greve, foram presos os diretores da Associação, o padre de Barcarena, que estava fotografando o movimento, e o carro da Associação. Em passeata, os trabalhadores exigiram a liberação de todos, o que foi conseguido, além da garantia de comida e água para os grevistas, medida que permitiu a ocupação dos alojamentos e das dependências da ALBRAS durante os seis dias de greve. A greve terminou após ampla consulta aos trabalhadores. Eles conquistaram o maior salário da construção civil do país, ganho de produtividade, um salário a mais a cada ano, o pagamento em dinheiro até as 18 horas, $10 \%$ de produtividade para quem trabalhava em tubulações, antecipação salarial de 20\% do salário, refeição gratuita ou dinheiro correspondente para quem fizesse serão depois das 20 horas, pagamento imediato do aviso prévio, transporte gratuito para Vila do Conde, Abaetetuba, Itupanema, São Francisco, alimentação unificada e IS de julho como dia do trabalhador da construção civil, com dispensa remunerada.

A greve de 1985 foi novamente uma ação organizada antes da campanha salarial. Com a experiência da greve anterior, foram realizadas assembléias nos locas de moradia e foram preparadas propostas de acordo coletivo. A ALBRAS, preocupada com a possibilidade de nova greve, mandou construir um quartel da PM no núcleo urbano e convocou os diretores da associação para avisar que não agiria da mesma forma, ou seja, não impediria a repressão ao movimento. Outra novidade: as negociações foram conduzidas, pelo lado dos patrões, por advogados 
da Federação das Indústrias do Estado de São Paulo (FIESP), que não aceitaram mais a representação do sindicato patronal do Pará.

Para os trabalhadores, a fiscalização do acordo anterior foi muito desgastante, na medida em que era quase impossível fiscalizar todas as empresas, o que era agravado pela ausência de uma política de garantia dos direitos trabalhistas nos canteiros de obras. A Associação produziu uma cartilha com o acordo coletivo assinado e distribuiu-a nas empresas. Essa cartilha teve o objetivo de divulgar as informações sobre o acordo coletivo, para tornar públicos os direitos conquistados, permitindo o acesso de todos às informações, porém o acordo foi redigido em uma linguagem cheia de termos jurídicos, o que permitia a burla do acordo por parte dos patrões, que sabiam manusear a linguagem jurídica e confundir os trabalhadores.

Assim, uma das discussões mais ricas da campanha salarial de 1985 foi sobre a linguagem em que o novo acordo deveria ser redigido. Mais uma vez, os trabalhadores tinham conhecimento das suas limitações e enfrentaram situações adversas para garantir seus direitos. Acordaram em assembléia que as cláusulas do novo acordo deveriam ser votadas com sua redação final e que a linguagem empregada deveria ser direta, afirmativa, evitando-se temos evasivos, como "poderá", "deverá", etc. A questão do poder da comunicação e da garantia de direitos pela leitura da lei, ou pelo menos sua possibilidade, era fundamental para uma categoria que ainda hoje conta com um grande número de analfabetos.

O papel dos advogados foi muito discutido, ficando acertado que eles não deveriam pronunciar-se nas negociações a não ser quando fossem chamados para dar uma opinião sobre algum aspecto legal, ou seja, os trabalhadores exigiram que a palavra e a negociação ficassem com eles. Nessa greve, foi garantido novamente o maior salário da construção civil do Brasil para Barcarena, adiantamento salarial, reajuste de um sexto do Índice Nacional de Preços ao Consumidor (INPC) em maio, novo adiantamento em agosto, com a data base voltando a ser o dia $1 .^{\circ}$ de novembro, estabilidade de 60 dias, após retorno de licença médica por acidente de trabalho. Além disso, as empresas concordaram em fornecer as ferramentas de trabalho.

Os trabalhadores da construção civil inseriram seus conceitos na história, com base em suas experiências de vida. Exemplo disso foi o uso do terminal rodoviário, que passou a ser um espaço de trabalho, na medida em que é o espaço das assembléias. Os trabalhadores discutem conceitos de cidadania e de Estado quando exigem a presença de políticas públicas nas relações de trabalho, a presença do Estado como fiscal dos seus direitos. 
Eles lidavam com problemas levantados pelo relativismo na constituição de sua identidade operária. Perceberam a transitoriedade dos valores culturais no processo de formação de sua identidade operária. A oposição entre trabalhador de trecho e trabalhador de casa não foi considerada como uma carga de definições fixas ou inatas. Nas experiências desses sujeitos históricos, essa oposição foi trabalhada no sentido de vencer as polaridades e propiciar a construção de uma identidade. No nosso entendimento, não houve uma ruptura com as novas formas de organização do capital; o que aconteceu foi uma reelaboração de práticas culturais em outro contexto, o que possibilitou a constituição de uma cultura operária do alojamento.

Uma nova identidade foi construída com base na diversidade cultural e nas experiências no espaço do trabalho, do alojamento, que foram reelaboradas nas lutas dos trabalhadores. Pela suas práticas, os trabalhadores criticam a modernidade racionalizadora, na medida em que questionam a imagem de um novo ciclo, criticando a irracionalidade dos projetos de desenvolvimento, definindo o lugar e a situação de seus interesses. Assumem o uma sensação de desenraizamento em relação à modernidade, experimentada na troca de hábitos no processo de trabalho. A modernidade dos grandes projetos e a modernidade do capital implica a perda de grande parte da autonomia dos trabalhadores. Eles têm consciência de que a dicotomia entre o moderno e o arcaico não é uma separação absoluta, que não corresponde à divisão entre o bem e o mal.

O processo tecnológico é concebido pelos trabalhadores como separado das suas experiências no trabalho. Eles rejeitam o discurso da modernização tecnológica, por compreenderem que isso não resolve o problema do desemprego e do desgaste físico do trabalhador. Para eles, o progresso tecnológico não é um pressuposto de modernidade. Está bem claro nas suas falas e práticas que esse progresso veio destruir valores, estabelecer conflitos no interior do processo de trabalho, enfim, os trabalhadores perceberam que o progresso beneficia o capital.

As ações realizadas, em função da conquista de reivindicações imediatas, indicam que os trabalhadores têm consciência dos direitos não respeitados pelos patrões. Constituiu-se uma parte da identidade operária, há uma certa consciência das condições de trabalho, entendidas como direitos. Dessa forma, os trabalhadores exercitaram a cidadania, cobrando do Estado a defesa de seus interesses, como membros de uma sociedade. A relação que estabelecem com o capital é vivida no cotidiano de suas lutas, nas quais se exige do governo transporte, saúde e segurança, nos conflitos entre o capital e o trabalho. 
Havia uma postura crítica em relação às leis trabalhistas, discutiuse a interpretação das leis e exigiu-se seu cumprimento. A disputa estabeleceu-se em campos diferenciados, ou seja, no terreno da legalidade e no terreno social. A busca de soluções imediatas para os conflitos não alimentou a ilusão de um projeto de harmonia social. $\mathrm{Na}$ verdade, os trabalhadores aceitaram disputar com seus patrões e discutir no terreno do direito, sabendo que limites eram impostos às suas reivindicações. O direito foi vivenciado como um campo de possibilidades e um espaço de lutas. O cumprimento da legislação e dos acordos coletivos é um problema social, que deve ser resolvido. Apesar de não acabarem com os conflitos, os acordos coletivos e a legislação vigente impõem limites à exploração.

Os trabalhadores da construção civil de Barcarena estabeleceram uma lógica e questionaram o direito dos seus patrões. As greves foram as formas utilizadas para reafirmar seus direitos e sua identidade coletiva. Os trabalhadores apresentam-se à sociedade como sujeitos históricos, possuidores de uma consciência operária. Tiveram uma percepção do conceito de justiça e questionaram a autoridade de seus patrões sobre suas vidas e seus trabalhos. 


\section{REFERÊNCIAS}

DIAS, M. O. L. S. Teoria e metodologia dos estudos feministas: perspectiva histórica e hermenêutica do cotidiano. In: COSTA, A. O.; BRUSCHINI, C. (Org.). Uma questão de gênero. Rio de Janeiro: Rosa dos Tempos; São Paulo. Fundação Carlos Chagas, 1992.

HARDMAN, F. F. Trem fantasma: a modernidade na selva. São Paulo: Companhia das Letras, 1988.

KOSELLECK, R. Futures past: on the semantics of historical time. Boston: The MIT Press, 1985.

PINTO, Lúcio Flávio. Jari: toda a verdade sobre o projeto de Ludwig (as relacões entre estado e multinacional na Amazônia). São Paulo: Marco Zero. 1986.

THOMPSON, E. P. A formação da classe operária inglesa. Rio de Janeiro: Paz e Terra, 1987. 